Diabetologia 10, $189-191(1974)$

(C) by Springer-Verlag 1974

\title{
Chlorpromazine in the Treatment of Endogenous Organic Hyperinsulinism*
}

\author{
G. Federspil, D. Casara and W. Stauffacher \\ Institute of Semeiotica Medica, University of Padua, Italy, Medizinische Universitätsklinik, Bern, and Institute of \\ Histology, University of Geneva, Switzerland \\ Received: August 13, 1973, and in revised form: December 10, 1973
}

\begin{abstract}
Summary. A 26 year old woman with fasting spontaneous hypoglycaemia and organic hyperinsulinism. (probable insulinoma) who had obtained no improvement after a $2 / 3$ pancreatectomy was treated for over a year with Chlorpromazine $(50 \mathrm{mg} / \mathrm{day})$. The treatment has considerably increased the fasting blood glucose level and has significantly lowered the basal insulin concentrations. After an oral glucose load insulin secretion. appeared to be clearly reduced when compared to the pre-treatment values. Nausea and hirsutism which had
\end{abstract}

become evident during a previous treatment with Diazoxide, disappeared completely on Chlorpromazine. Furthermore no important side effects were noted. The role of Chlorpromazine in the treatment of organic hyperinsulinism is discussed.

Key words: Chlorpromazine, diazoxide, hypoglycemia, insulinoma, insulin secretion, oral glucose tolerance test, organic hyperinsulinism.
The choice of drugs presently available for the effective prevention of hypoglycaemia secondary to endogenous hyperinsulinaemia in patients with presumed but surgically not proven benign islet-cell adenomas is limited to Diazoxide administered alone or in association with thiazide-diuretics [1], glucocorticoids or glucagon. Since Diazoxide is frequently ineffective at dosage levels tolerated by the patients and since the use of betacytotoxic agents such as Streptozotocin is precluded in cases without proven metastatic malignancy, a therapeutic alternative or complement to Diazoxide is desirable for the use in patients intolerant or unresponsive to Diazoxide.

Reports of hyperglycaemia and of non-ketotic hyperglycaemic coma occurring in patients treated with Chlorpromazine (CPZ) for psychiatric reasons $[2,3]$, the recent observation of an inhibitory effect of CPZ on glucose-induced insulin release in rat islets of Langerhans in vitro $[4,5]$ and a preliminary communication suggesting a favorable effect of CPZ in a patient with islet cell carcinoma [6] have prompted the authors to use CPZ in a patient suffering from organic hyperinsulinism in whom operation failed to improve the persistent tendency to hypoglycaemia. Although Diazoxide alleviated the hypoglycaemic attacks and reduced the concentrations of circulating insulin, an alternative mode of treatment had to be sought since at effective dose levels, the drug induced persistent nausea and cosmetically intolerable hirsutism and since the patient and her family refused further investigation or a second surgical intervention.

* Supported in part by the grant $\mathbf{n}^{0}$ 71. 0071. 04 of Consiglio Nazionale delle Ricerche (Italy) and by the grant $\mathrm{n}^{0} 3.8080 .72 \mathrm{~S}$. R. of Fonds National de la Recherche Seientifique Suisse.

\section{Case History}

In 1969 C. $A$., a previously healthy 26 year old woman, began to exhibit episodes of abnormal behaviour accompanied by tremor and seizures without loss of consciousness in the morning before breakfast.

Hypoglycaemia was suspected and in January 1971 the patient was admitted to this hospital. Fasting blood glucose concentration (glucose-oxidase) varied between 19 and $43 \mathrm{mg} / 100 \mathrm{ml}$ (mean $31 \mathrm{mg} / 100 \mathrm{ml}$ ). Fasting plasma insulin (IRI; Hales and Randle) level oscillated between 65 and $260 \mu \mathrm{U} / \mathrm{ml}$ (mean $162 \mu \mathrm{U} / \mathrm{ml}$ ). During a tolbutamide and a leucine tolerance test excessive IRI-responses, profond hypoglycaemia and coma occurred; after glucagon i.v. (1 mg) plasma insulin rose from 65 to $330 \mu \mathrm{U} / \mathrm{ml}$.

Appropriate tests failed to reveal abnormal function of the hypophysis, adrenals, thyroid or liver. A diagnosis of an insulin producing pancreatic tumor was made. In April 1971 laparatomy was performed. No pancreatic or extrapancreatic abdominal tumor was detected. A 2/3 pancreatectomy was performed. Subsequent careful histological scrutiny of the removed tissue failed to reveal an adenoma or diffuse islet hyperplasia or hypertrophy. The operation resulted in no improvement of the patients condition, in that hypoglycaemic attacks continued to occur and plasma IRI concentrations remained unchanged. Treatment with Diazoxide (300 $\mathrm{mg} /$ day) and Bendroflumethiazide (5mg/day) was started. Fasting blood glucose concentrations rose immediately and plasma insulin fell to about $1 / 3$ of the values measured before treatment but remained elevated above normal level (mean $\pm S$ D: $19 \pm 7 \mu \mathrm{U} / \mathrm{ml}$ ) (Table 1 ). The hypoglycaemic attacks subsided with the exception of an occasional feeling of dizziness. Subsequently she experienced persistent 
nausea and developed cosmetically disturbing hirsutism. For these reasons Diazoxide and Bendroflumethiazide were discontinued and the patient received Chlorpromazine as from December 1971.
The results obtained with CPZ appear encouraging, but the mechanism by which this drug exerted its favorable effect in this patient have not been studied in detail.

Table 1. Blood glucose and plasma IRI during different treatment periods

\begin{tabular}{|c|c|c|c|}
\hline & $\begin{array}{l}\text { Blood Glucose } \\
(\mathrm{mg} / \mathbf{1 0 0} \mathrm{ml})\end{array}$ & $\begin{array}{l}\text { Plasma IRI } \\
(\mu \mathrm{U} / \mathrm{mI})\end{array}$ & Glucose/IRI \\
\hline $\begin{array}{l}\text { No treatment } \\
\text { Diazoxide }+b\end{array}$ & $31 \pm 1$ & $162 \pm 22(8)$ & $0.24 \pm 0.05$ \\
\hline Bendroflumethiazide & $54^{\mathrm{a}} \pm 3(25)$ & $40^{\mathrm{a}} \pm 5(21)$ & $1.85^{\mathrm{a}} \pm 0.29(21)$ \\
\hline Chlorpromazinec & $44^{a} \pm 2(19)$ & $55^{a} \pm 4(19)$ & $0.94^{\mathrm{a}} \pm 0.13(16)$ \\
\hline
\end{tabular}

The dose was progressively increased from 25 to $75 \mathrm{mg} /$ day, at which dose the patient complained of slight somnolence during the day. A maintenance dose of $50 \mathrm{mg} /$ day was the given. As shown by the data presented in Table 1 , blood glucose concentrations were slightly lower and plasma IRI values slightly higher than those measured while the patient received Diazoxide. Despite this, the patients condition improved dramatically, nausea and hirsutism disappeared completely. No hypoglycaemic attacks occurred and the episodes of slight dizziness did not occur more frequently than with Diazoxide. The patient felt completely well and refused further investigation or another operation. One year after the beginning of the CPZ treatment an oral glucose tolerance test $(100 \mathrm{~g}$ in $200 \mathrm{ml}$ lemonade) was performed in order to obtain a comparison with an identical test performed before the start of the Diazoxide treatment. The results of both tests are represented in Fig. 1 and show that, apart from the low basal glucose concentration and the elevated IRI value at $0 \mathrm{~min}$, the curves obtained under CPZ were practically normal and clearly different from those obtained before the onset of treatment.

\section{Discussion}

Although we were unable to prove the existence of an insulinoma in this patient, continuous fasting hyperinsulinaemia as well as excessive IRI-responses to leucine, tolbutamide and glucagon argue strongly in favor of this clinical diagnosis. The existence of pancreatic malignancy can be ruled out on basis of the duration of the disease and in view of the patients excellent state of health which persists up to now. Unfortunately the patient refuses both further investigation in order to localize and to remove her adenoma and a controlled attempt to withdraw treat. ment.
Ammon and Steinke [4] and Orci et al. [5] have shown that, in isolated islets of Langerhans from the rat, CPZ interferes with glucose-induced insulin release and causes a dose-dependent increase in the number of autophagosomes in the $\beta$-cells. Although the concentrations used in vitro by these workers are likely to be higher than those achieved in the islets of Langerhans of our patient with a dose of $50 \mathrm{mg} /$ day, and although other possible effects of the drug on glucose metabolism have not been excluded, impairment of insulin secretion by the abnormal islet tissue appears to have been an important, possibly the principal factor responsible for the favorable response

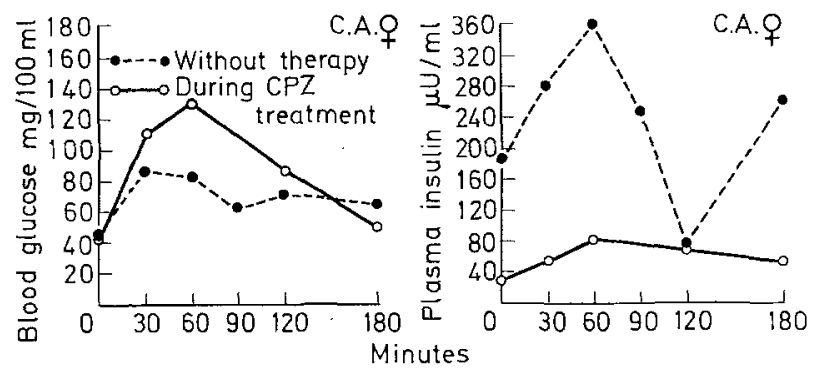

Fig. 1. Effect of CPZ treatment on oral glucose tolerance test

to treatment with CPZ. Indeed, and as evidenced by the data shown in table 1 and figure 1, a considerable reduction of both basal and glucose-induced insulin secretion occurred under the treatment and persisted for a prolonged period of time.

As judged from the biological data obtained in our patient (Table 1), CPZ, at the dose used, appears to be less effective in suppressing insulin secretion than Diazoxide (300 $\mathrm{mg} /$ day) in association with a thiazide-diuretic. The higher dose $(75 \mathrm{mg} /$ day) could not be given long enough to allow satisfactory evaluation. 
Moreover, since CPZ, unlike Diazoxide, at the maintenance dose chosen was completely devoid of side effects, its therapeutic efficiency was considered superior to that of Diazoxide by both patient and physicians. It is therefore thought that $\mathrm{CPZ}$ should be tested as a potentially useful alternative to Diazoxide in the treatment of endogenous hyperinsulinism, and that its clinical usefulness in the various pathogenetic forms of this condition should be tested and defined.

Acknowledgements. We wish to express our thanks to Dr. L. Orci for his helpful advice.

\section{References}

1. Austoni, M., Scandellari, C., Trisotto, A., Federspil, G. (eds.): Hypoglycaemia and Diazoxide, p. 428. Padova: Cedam 1972
2. Gerich, J.E., Martin, M.M., Recant, L.: Clinical and metabolic characteristics of hyperosmolar nonketotic coma. Diabetes 20, 228-238 (1971)

3. Waitzkin, L.A.: A Survey for unknown diabetes in a mental hospital. Diabetes 15, 164-172 (1966)

4. Ammon, H.P.T., Steinke, J.: Apparent biphasic action of chlorpromazine (CPZ) on insulin release from isolated pancreatic rat islets. Diabetes 15, 345 (1971) (Abstract)

5. Orei, L., Ammon, H.P.T., Steinke, J.: The effect of chlorpromazine (CPZ) on insulin release from isolated pancreatic rat islets: A correlated morphological and biochemical study. Diabetologia 8, 61 (1972) (Abstract)

6. Lambert, A.E., Henquin, J.C., Orci, L.: Use of chlorpromazine in the prevention of hypoglycemia in malignant insulinoma Brit. med. J. 1972 3, 701

Dr. G. Federspil

Istituto di Semeiotica Medica

Via Ospedale Civile 43

Padova 35100

Italy 